\title{
Strain and process development for poly (3HB-co-3HP) fermentation by engineered Shimwellia blattae from glycerol
}

\author{
Shunsuke Sato ${ }^{1}$, Björn Andreeßen ${ }^{1}$ and Alexander Steinbüchel ${ }^{1,2^{*}}$
}

\begin{abstract}
Poly(3-hydroxybytyrate-co-3-hydroxypropionate), poly(3HB-co-3HP), is a possible alternative to synthetic polymers such as polypropylene, polystyrene and polyethylene due to its low crystallinity and fragility. We already reported that recombinant strains of Shimwellia blattae expressing 1,3-propanediol dehydrogenase DhaT as well as aldehyde dehydrogenase AldD of Pseudomonas putida KT2442, propionate-CoA transferase Pct of Clostridium propionicum X2 and PHA synthase PhaC1 of Ralstonia eutropha H16 are able to accumulate up to $14.5 \%$ (wtPHA $/ \mathrm{wt}_{\mathrm{CD}}$ ) of poly(3-hydroxypropionate), poly(3HP), homopolymer from glycerol as a sole carbon source (Appl Microbiol Biotechnol 98:7409-7422, 2014a). However, the cell density was rather low. In this study, we optimized the medium aiming at a more efficient PHA synthesis, and we engineered a S. blattae strain accumulating poly(3HB-co-3HP) with varying contents of the constituent 3-hydroxypropionate (3HP) depending on the cultivation conditions. Consequently, 7.12, 0.77 and $0.32 \mathrm{gPHA} / \mathrm{L}$ of poly(3HB-CO-3HP) containing 2.1, 8.3 and $18.1 \mathrm{~mol} \% 3 \mathrm{HP}$ under anaerobic/aerobic (the first 24 hours under anaerobic condition, thereafter, aerobic condition), low aeration/agitation (the minimum stirring rate required in medium mixing and small amount of aeration) and anaerobic conditions (the minimum stirring rate required in medium mixing without aeration), respectively, were synthesized from glycerol by the genetically modified S. blattae ATCC33430 strains in optimized culture medium.
\end{abstract}

Keywords: Copolymerization ratio; Fermentation condition; Glycerol; Poly(3HB-co-3HP); Shimwellia blattae

\section{Introduction}

Polyhydroxyalkanoates (PHA) are polyesters synthesized by a wide range of microorganisms (Anderson et al., 1990). Most of PHA are produced from renewable resources like sugars, plant oils, glycerol, and carbon dioxide $\left(\mathrm{CO}_{2}\right)$. As these polyesters are biodegradable, they have been expected to play an important role in environmental protection and in reduction of $\mathrm{CO}_{2}$ emissions, a cause of global warming (Steinbüchel and Füchtenbusch, 1998). There have been many attempts to investigate industrial production of such polymers to ascertain if they are environmently friendly or biocompatible materials (Lee, 1996; Steinbüchel, 2001). In nature, poly(3-hydroxybutyrate), poly(3HB), a homopolymer of $(R)$-3-hydroxybutyric

\footnotetext{
* Correspondence: steinbu@uni-muenster.de

${ }^{1}$ Institut für Molekular Mikrobiologie und Biotechnologie, Westfälische Wilhelms-Universität Münster, Corrensstraße 3, D-48149 Münster, Germany ${ }^{2}$ Environmental Sciences Department, Faculty of Meteorogy, Environment and Arid Land Agriculture, King Abdulaziz University, Jeddah, Saudi-Arabia
}

acid (3HB), is the most abundant PHA. However, because poly $(3 \mathrm{HB})$ is highly crystalline, hard and brittle, its practical applications are limited. Many studies have been undertaken to improve these properties. For example, among other PHA, poly(3-hydroxybutyrate-co-3-hydroxyvalerate), poly(3HB-co-3HV), poly(3-hydroxybutyrate-co-3-hydroxyhexanoate), poly(3HB-co-3HH), and poly(3-hydroxybutyrate-co-3-hydroxypropionate), poly(3HB-co-3HP) are much more flexible and less crystalline than poly $(3 \mathrm{HB})$ (Andreeßen et al., 2014b; Chen et al., 2000; Doi et al., 1995; Shimamura et al., 1993; Shimamura et al., 1994). The flexibility depends on the ratio of the constituents in the copolymer. Therefore, these copolymers are accordingly expected to have a broader range of applications in packaging, agriculture and medical materials (Chen et al., 2000). Among these copolymers, poly (3HB-co-3HP) is considered to be very promising due to its benefiting material properties (Andreeßen and Steinbüchel, 2010). 
The global glycerol production has increased rapidly during the last decade due to the increase of biodiesel production. Concomitant with the conversion of about 10 million tons of vegetable oil into biofuel, about 1 million tons of glycerol were produced as a by-product in 2011 (Quispe et al. 2013). Therefore, the aim of this study was the development of strains for poly(3HB-co$3 \mathrm{HP})$ synthesis from glycerol as sole carbon source.

Some processes for synthesis of poly(3HB-co-3HP) have already been reported by Shimamura et al., 1994, Fukui et al., 2009, Wang and Inoue, 2001 and Wang et al., 2013. However, in these studies the use of expensive $3 \mathrm{HP}$ as precursor of $3 \mathrm{HP}-\mathrm{CoA}$ (Shimamura et al., 1994; Wang and Inoue, 2001), insufficient 3HP contents to reduce the crystallinity (Fukui et al., 2009) and the requirement of high cost vitamin $\mathrm{B}_{12}$ are major drawbacks (Wang and Inoue, 2001; Wang et al., 2013).

Vitamin $B_{12}$ is a cofactor of the glycerol dehydratase (Martens et al., 2002), which converts glycerol to 3hyrdoxypropionaldehyde (3HPA), a precursor of 3HPCoA (Wang et al., 2013), to produce 1,3-propanediol (1,3PD). However, only few bacteria are capable of synthesizing vitamin $B_{12}$ (Sun et al., 2003). To solve this problem, we used the enteric bacterium Shimwellia blattae ATCC33430 (Burgess et al., 1973; Priest and Barker, 2010) which cannot naturally produce PHA but synthesizes vitamin $B_{12}$ (Andres et al., 2004) and converts glycerol to $1,3 \mathrm{PD}$.

Recently, we reported that $S$. blattae expressing 1,3propanediol dehydrogenase (dhaT) and aldehyde dehydrogenase (aldD) of Pseudomonas putida KT2442, propionate-coenzyme A (propionate-CoA) transferase (pct) of Clostridium propionicum X2, and PHA synthase (phaC1) of Ralstonia eutropha H16 accumulates poly (3HP) from glycerol as a sole carbon source up to $14.5 \%$ ( $\mathrm{wt}_{\mathrm{PHA}} / \mathrm{wt}_{\mathrm{CDW}}$ ) (Andreeßen et al., 2014a; Heinrich et al., 2013). Here, 1,3PD produced by $S$. blattae is oxidized first to $3 \mathrm{HPA}$ by DhaT and subsequently to $3 \mathrm{HP}$ by AldD. 3HP is then activated by addition of coenzyme A by Pct. In order to synthesize poly (3HB-co-3HP) from glycerol in S. blattae, we co-expressed phaA and phaB1 from R. eutropha H16 (Budde et al., 2010) together with the enzymes for the already mentioned artificial poly (3HP) pathway (Heinrich et al., 2013). Two molecules of acetyl-CoA are condensed to acetoacetyl-CoA by a $\beta$ ketothiolase (PhaA) and acetoacetyl-CoA is then reduced by an $(R)$-specific acetoacetyl-CoA reductase (PhaB1) to generate ( $R$ )-3HB-CoA. As a result, the recombinant $S$. blattae (Sb6BP) is capable of synthesizing poly(3HB-co-3HP) (Figure 1).

However, the residual cell density was less than $6 \mathrm{~g} / \mathrm{L}$ and therefore too low to produce much poly(3HB-co3HP). Since PHA are accumulated inside the cells, low residual cell density result in only low PHA productivity.
For example, even if $90 \%\left(\mathrm{wt}_{\mathrm{PHA}} / \mathrm{wt}_{\mathrm{CDW}}\right)$ of poly(3HBco-3HP) is accumulated in a cell, less than $54 \mathrm{~g} / \mathrm{L}$ of polymer is produced under such conditions.

Therefore, an optimized culture medium was needed to overcome this problem. In this study, we report on a new strategy for synthesis of poly(3HB-co-3HP) using optimized cultivation medium and glycerol in genetically modified S. blattae without the addition of vitaminB $B_{12}$ and $3 \mathrm{HP}$ into the culture.

\section{Materials and methods}

\section{Strain and plasmid}

Table 1 lists all strains and plasmids used in this study. For cloning experiments, plasmids were transformed into Escherichia coli TOP10. For synthesis of poly(3HBco-3HP) or poly(3HB), S. blattae ATCC33430 was transformed with plasmid pBBR1MCS-2::plac::aldD:dhaT::pct:: $p_{\text {lac }}:$ phaC1AB.

\section{Growth of cells}

250-mL Erlenmeyer flasks containing $50 \mathrm{~mL} \mathrm{MMB}$ medium [3.56 g/L Na $\mathrm{PO}_{4} \cdot 2 \mathrm{H}_{2} \mathrm{O}, 0.68 \mathrm{~g} / \mathrm{L} \mathrm{KH}_{2} \mathrm{PO}_{4}$, $0.63 \mathrm{~g} / \mathrm{L}(\mathrm{NH} 4)_{2} \mathrm{SO}_{4}, 2.47 \mathrm{~g} / \mathrm{L} \mathrm{MgSO}_{4} \cdot 7 \mathrm{H}_{2} \mathrm{O}, 1.0 \%$ ( $\mathrm{vol} / \mathrm{vol})$ trace element solution $(0.1 \mathrm{~N} \mathrm{HCl}$ in $4.2 \mathrm{~g} / \mathrm{L}$ $\mathrm{FeSO}_{4} \cdot 7 \mathrm{H}_{2} \mathrm{O}, 5.0 \mathrm{~g} / \mathrm{L} \mathrm{CaCl}_{2} \cdot 2 \mathrm{H}_{2} \mathrm{O}, 2.4 \mathrm{~g} / \mathrm{L} \mathrm{CoCl}_{2} \cdot 6$ $\mathrm{H}_{2} \mathrm{O}, 0.58 \mathrm{~g} / \mathrm{L} \mathrm{CuCl} \cdot 2 \mathrm{H}_{2} \mathrm{O}, 2 \mathrm{mg} / \mathrm{L} \mathrm{NiCl}_{2} \cdot 6 \mathrm{H}_{2} \mathrm{O}$, $3 \mathrm{mg} / \mathrm{L} \mathrm{MnCl} \mathrm{Mn}_{2} \cdot 4 \mathrm{H}_{2} \mathrm{O}, 0.03 \mathrm{~g} / \mathrm{L} \mathrm{H}_{3} \mathrm{BO}_{3}, 4.3 \mathrm{~g} / \mathrm{L} \mathrm{ZnSO}_{4}$ • $7 \mathrm{H}_{2} \mathrm{O}, 3 \mathrm{mg} / \mathrm{L} \mathrm{NaMoO}_{4} \cdot 2 \mathrm{H}_{2} \mathrm{O}$ )] with $300 \mathrm{mM}$ of glycerol was used for optimization of culture medium. Cells were cultivated in 250-mL Erlenmeyer flasks at an agitation of $125 \mathrm{rpm}$ and at $30^{\circ} \mathrm{C}$. High cell density fed-batch cultivation of $S$. blattae were conducted in a $2 \mathrm{~L}$ jar fermenter (Biostat B plus, Sartorius AG, Göttingen, Germany) containing $1.5 \mathrm{~L}$ of basal medium (BM) (Andreeßen et al. 2014a,b) or MMB medium with $300 \mathrm{mM}$ of glycerol as carbon source.

Glycerol was intermittently added to the culture medium to maintain a concentration between 50 and $300 \mathrm{mM}$. 500-mL flasks containing $100 \mathrm{~mL} \mathrm{BM}$ or MMB medium, $300 \mathrm{mM}$ of glycerol and $50 \mu \mathrm{g} / \mathrm{L}$ of kanamycin were used for seed cultivations. Dissolved oxygen was monitored and $\mathrm{pH}$ was controlled in the range of $6.8-6.9$ by using a $7.5 \%$ aqueous solution of ammonium hydroxide.

Plasmid construction and transfer into $E$. coli and S. blattae All processing and manipulation of DNA was carried out as described by Sambrook et al., 1989. Plasmid pBHR68 (Spiekermann et al., 1999) was digested with Bsp119I and EcoRI to generate a 4.2-kbp fragment comprising the coding regions of phaCl, phaA and phaB1. This fragment was ligated to the ClaI and EcoRI restriction fragment of pBBR1MCS-2 (Kovach et al., 1995) to generate pBBR1MCS-2:: $p_{\text {lac }}:$ phaC1AB. 


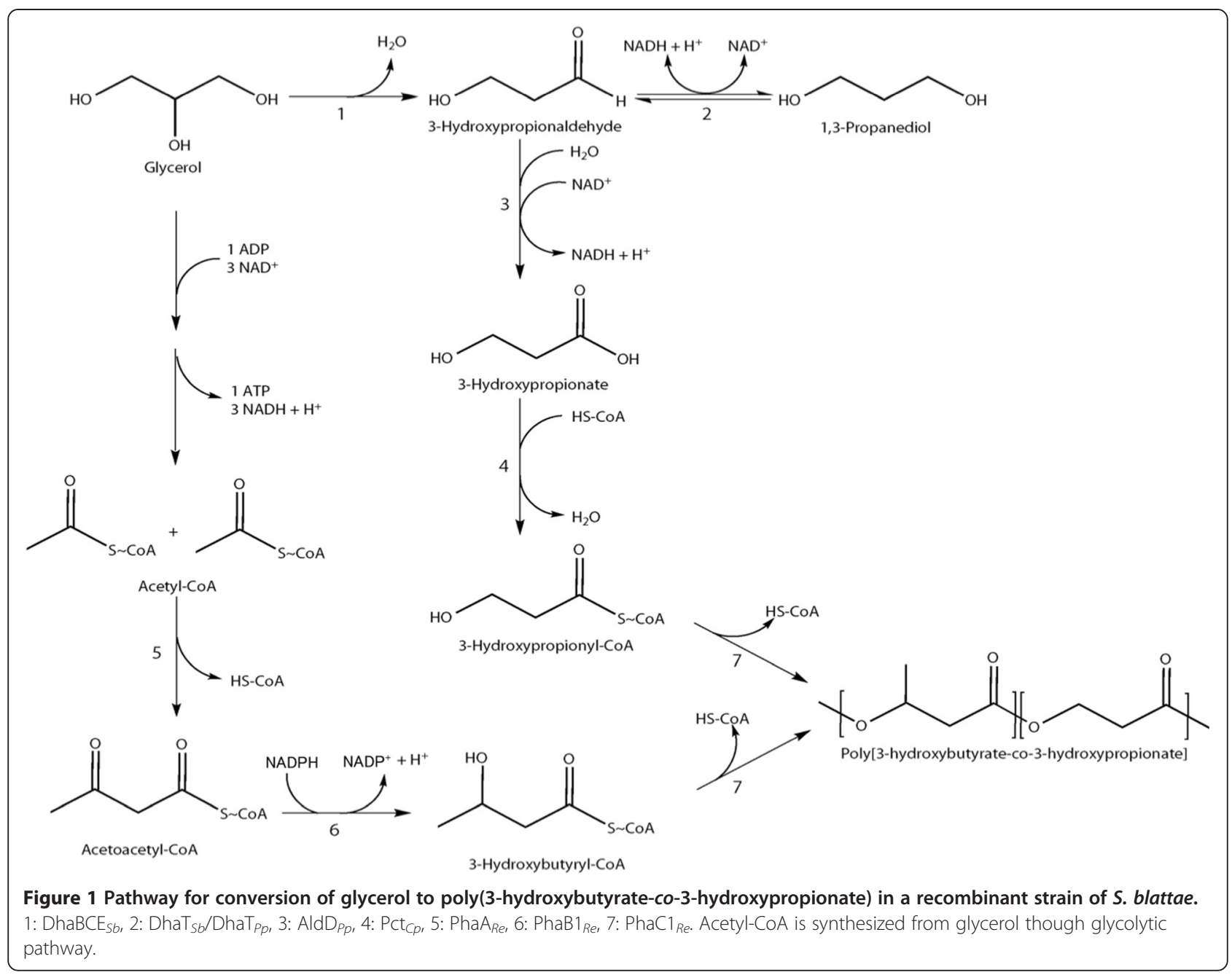

Table 1 Bacterial strains and plasmids used in this study

\begin{tabular}{|c|c|c|}
\hline Strains and plasmids & Relevant characteristics & Origin or reference \\
\hline \multicolumn{3}{|l|}{ Strains } \\
\hline \multicolumn{3}{|l|}{ E. coli } \\
\hline TOP10 & 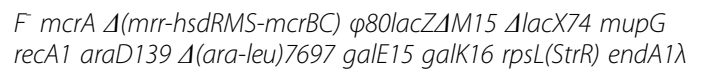 & $\begin{array}{l}\text { Life technologies } \\
\text { (Darmstadt, D) }\end{array}$ \\
\hline \multicolumn{3}{|l|}{ S. blattae } \\
\hline ATCC33430 & Wild type strain & ATCC33430 \\
\hline Sb6BP & $\begin{array}{l}\text { pBBR1MCS-2 ::plac::aldD::.dhaT:: pct::plac::phaC1AB in S. blattae } \\
\text { ATCC } 33430\end{array}$ & This study \\
\hline \multicolumn{3}{|l|}{ Plasmids } \\
\hline pBBR1MCS-2 & Cloning vector, $\mathrm{Km}^{\mathrm{r}}$ & Kovach et al., 1995 \\
\hline pBBR1MCS-2 ::aldD::dhaT::pct & $\mathrm{Km}^{\mathrm{r}} ;$ aldD $D_{p p} ;$ dhat $T_{p p} ; p c t_{c p}$ & Heinrich et al., 2013 \\
\hline pBBR1MCS-2 ::plac::phaC1AB & $\mathrm{Km}^{\mathrm{r}}$; phaC1 $1_{R e i}$ phaA Rei $p h a B 1_{R e}$ & This study \\
\hline pBBR1MCS-2 ::plac::aldD:::dhaT::pct ::plac::phaC1AB & $\mathrm{Km}^{\mathrm{r}}$; aldD $D_{P p} ;$ dhaT $T_{p p i} p c t_{C p i} p h a C 1_{R e i} p h a A_{R e i} p h a B 1_{R e}$ & This study \\
\hline
\end{tabular}


Then, pBBR1MCS-2:: lac $_{\text {lac }}:$ phaC1AB was digested with $S s p$ I to generate a $4.7-\mathrm{kbp}$ expression cassette of the phaC1, phaA and phaB1 under control of the lac promoter and ligated with the EcoICRI linearized fragment of pBBR1MCS-2::aldD::dhaT::pct (Heinrich et al., 2013) to generate the expression vector pBBR1MCS-2::

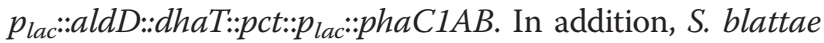
ATCC33430 was transformed with pBBR1MCS-2:: $p_{\text {lac }}:$ : aldD::dhaT::pct::plac::phaC1AB to generate $S b 6 \mathrm{BP}$ by electroporation as previously described (Heinrich et al., 2013).

\section{Optimization of cultivation medium}

When optimizing the medium, we thought yeast extract is not necessary, because cultivations in complete synthetic medium have been made for bacteria such as Klebsiella pneumonia (Brandl et al., 1998), E. coli (Enayati et al., 1999) or R. eutropha (Sato et al., 2013). Therefore, several different concentrations of yeast extract were tested as described below.

250-mL Erlenmeyer flasks containing $50 \mathrm{~mL}$ MMB medium with $0,0.2$ or $2.0(\mathrm{~g} / \mathrm{L})$ of yeast extract, respectively were used to cultivate $S$. blattae ATCC33430. The optical density at $600 \mathrm{~nm}$ and the $\mathrm{pH}$ were measured in samples withdrawn from the culture. In order to decide which yeast extract concentration is favorable for high cell density cultivation, $2 \mathrm{~L}$ bioreactors containing $1.5 \mathrm{~L}$ of MMB medium with $300 \mathrm{mM}$ of glycerol and 0.2, 0.67 or $6.7 \mathrm{~g} / \mathrm{L}$ of yeast extract and Sb6BP were used. Cell densities $\left(\mathrm{g}_{\mathrm{CDW}} / \mathrm{L}\right)$ and polymer contents (\% $\mathrm{wt}_{\mathrm{PHA}} /$ $\mathrm{wt}_{\mathrm{CDW}}$ ) were measured.

\section{Synthesis and purification of poly(3HB-co-3HP)}

PHA was synthesized in a $2 \mathrm{~L}$ bioreactors containing $1.5 \mathrm{~L}$ of BM or MMB medium for 72 or $48 \mathrm{~h}$. Glycerol was used as sole carbon source. Generally, enteric bacteria also S. blattae synthesize 1,3PD only under anaerobic condition. Thus, 4 different cultivation conditions (aerobic, anaerobic, low aeration/agitation and two-step) were conducted to optimize poly (3HB-co-3HP) synthesize condition in recombinant S. blattae (SB6P).

The operating conditions were as follows: Aerobic condition means an agitation at $800 \mathrm{rpm}$ and an aeration rate of $2.0 \mathrm{~L} / \mathrm{min}$. Anaerobic conditions were maintained at an agitation of $150 \mathrm{rpm}$ without any aeration whereas low aeration/agitation conditions were provided at a stirring rate of $150 \mathrm{rpm}$ and an aeration rate of $0.4 \mathrm{~L} / \mathrm{min}$. $150 \mathrm{rpm}$ was the minimum stirring rate required in medium mixing. The two-step fermentation (the first 24 hours under anaerobic condition, thereafter, aerobic condition) was performed according to Heinrich et al., 2013.

\section{Cell harvest and extraction of poly(3HB-co-3HP)}

After separating the cells from the culture broth, cells were frozen at $-30^{\circ} \mathrm{C}$ and freeze dried. Poly $(3 \mathrm{HB}-c o-3 \mathrm{HP})$ or poly $(3 \mathrm{HB})$ was isolated from the pulverized dry cell matter by digestion of non-PHA biomass employing a $13 \%$ ( vol/vol) sodium hypochlorite solution (Heinrich et al., 2013, Heinrich et al., 2012).

\section{Determination of poly(3HB-co-3HP)}

Analysis of polymer content and purity of the extracted polymer was done by gas chromatography (GC). For this dried cell mass or samples of isolated poly (3HB-co-3HP) and poly $(3 \mathrm{HB})$ were exposed to acidic methanolysis as described before (Brandl et al., 1998; Timm et al., 1990). For microscopic analysis of PHA-granules cells were stained with Nile red (Spiekermann et al., 1999) (Figure 2).

\section{Determination of glycerol and 1,3PD}

Concentrations of glycerol and 1,3PD in the media were monitored by HPLC analysis. For this, supernatants were assayed using a Lachrom Elite HPLCSystem (VWR-Hitachi, Darmstadt, D) chromatograph with a RI-detector (Type 2490 VWR, Darmstadt, D) and a Metacarb 67H-column $(300 \times 6.5 \mathrm{mM}$, VWRVarian, Darmstadt, D) at $75^{\circ} \mathrm{C}$ and at a flow rate of $0.8 \mathrm{ml} /$ min for $20 \mathrm{~min}$. The mobile phase was $4.5 \mathrm{mM}$ sulfuric acid.

\section{Results}

Synthesis of poly(3HB-co-3HP) influenced by cultivation conditions

In order to develop a process for poly(3HB-co-3HP) production by a newly engineered Sb6BP strain, cultivation was conducted under four different conditions (aerobic, two-step, low aeration/agitation and aerobic conditions). (i) Aerobic condition occurred at high aeration and agitation, (ii) the two-step condition occurred during the first 24 hours under anaerobic condition and thereafter under aerobic condition, (iii) for low aeration/agitation condition a minimum stirring rate was applied together with low rate of aeration and (iv) for anaerobic condition was a minimum stirring rate was applied without aeration.

Glycerol supplementation started from 8 to 16 hours of cultivation in every culture when glycerol concentration became lower than $100 \mathrm{mM}$. In most cases, glycerol consumption rate became lower than supplementation rate after $18 \mathrm{~h}$ cultivation. If this was the case, the supplementation rate was regulated to maintain a glycerol concentration between 50 and $300 \mathrm{mM}$ during the cultivations. In case of $1,3 \mathrm{PD}$, it might not be effectively transported into the cell after it was transiently formed and excreted into the medium before it could be 


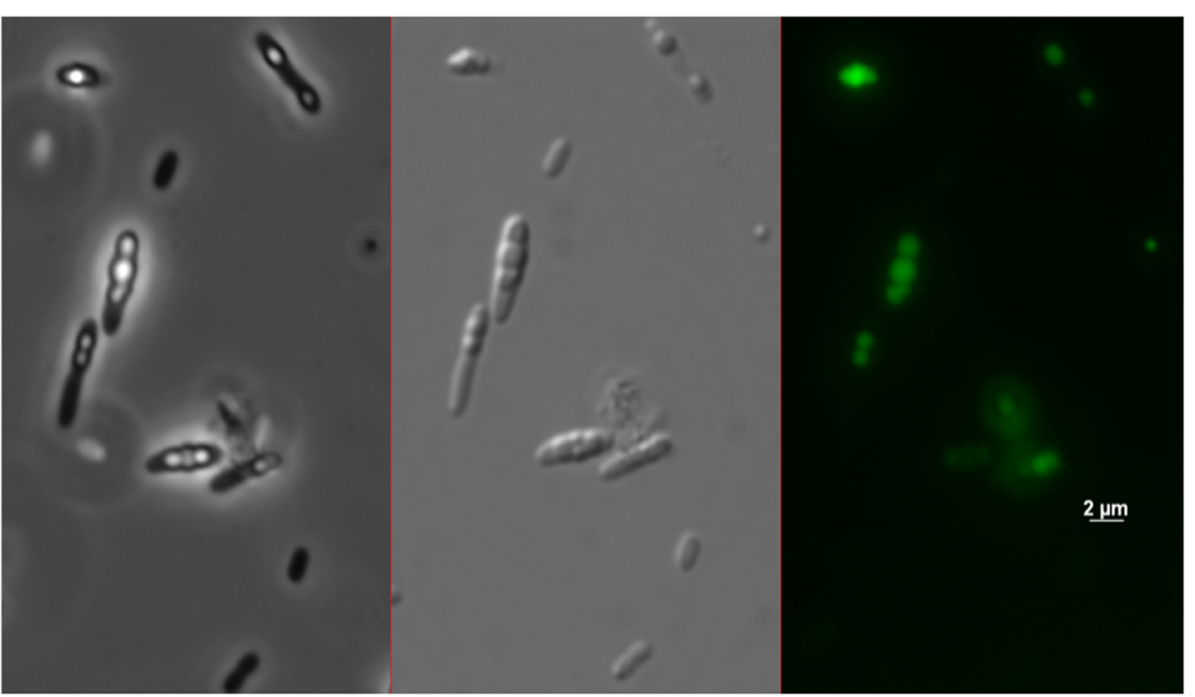

Figure 2 Poly(3HB-co-3HP) accumulation of Shimwellia blattae Sb6BP. After $72 \mathrm{~h}$ of fermentation in BM under two-step condition. Hydrophobic inclusions were stained with Nile red and observed with a fluorescence microscope employing phase contrast (left), differential interference contrast (middle), and fluorescence microscopy at $312 \mathrm{~nm}$ (right), respectively.

incorporated into the polymer via 3-hydroxypropionylCoA; thus the 1,3PD concentration was not so affected during cultivations. Moreover, the reduction of 1,3PD concentration in the later phase of the cultivation period could also occur due to a dilution effect (Figures 3 and 4).

The amount of 1,3PD that was converted into 3hydroxypropionyl-CoA and polymerized into poly(3HBco-3HP) was too small to affect the 1,3PD concentration of the culture medium in these studies. We already confirmed that 1,3PD supplemented to the culture medium was converted to 3-hydroxypropiony-CoA which is polymerized into poly(3HB-co-3HP) in the recombinant strain in which dhaT was heterologously expressed. However, efficiency was very low (data not shown). Therefore, most of the 3HP monomer in the accumulated polymer was provided directly from 3-hydroxypropionaldehyde via 3-hydroxypropionate and 3-hydroxyproionyl-CoA by AldD and Pct, respectively.

Strain Sb6BP was confirmed as a poly(3HB-co-3HP) producer (Table 2). Moreover, strain Sb6BP synthesized the poly(3HB-co-3HP) copolymer only under anaerobic, two-step and low aeration/agitation conditions. Under

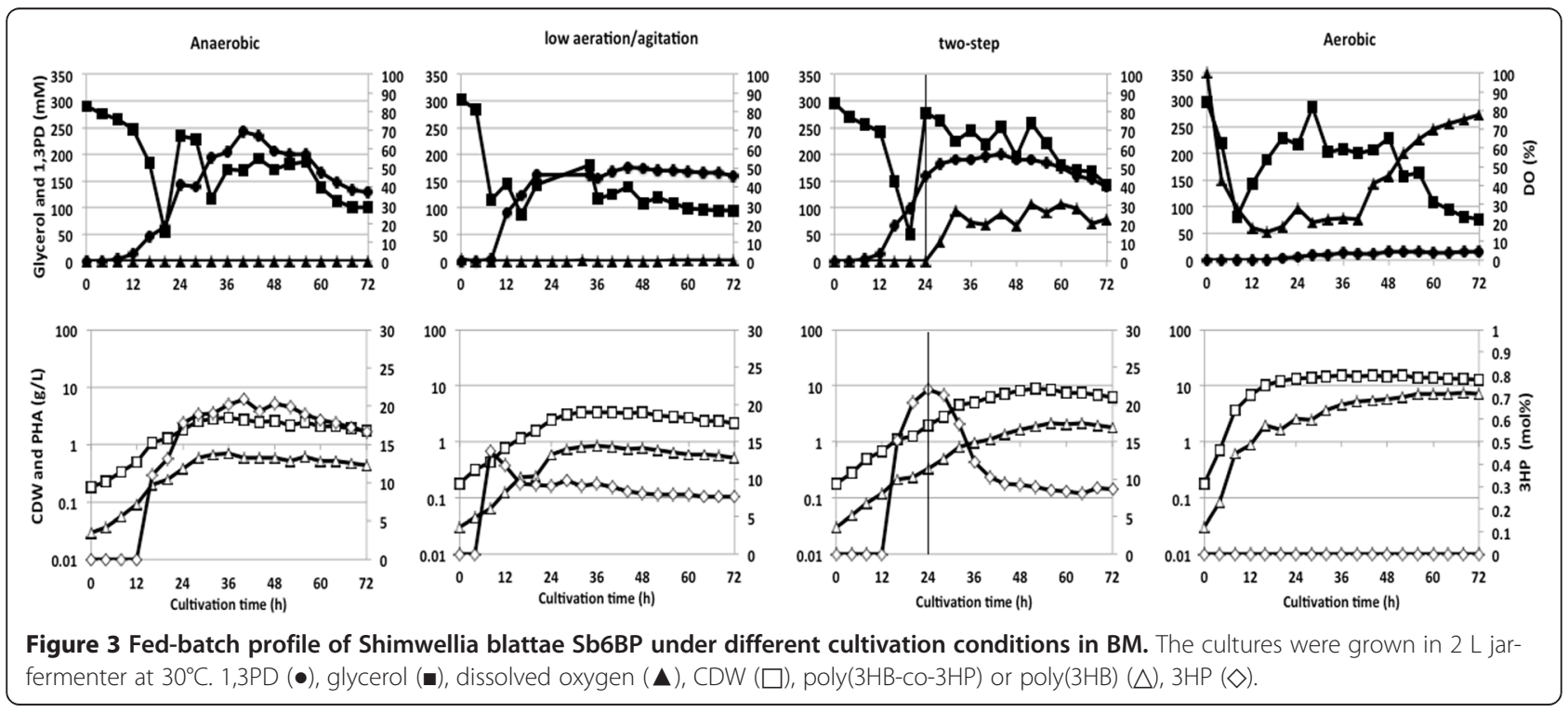




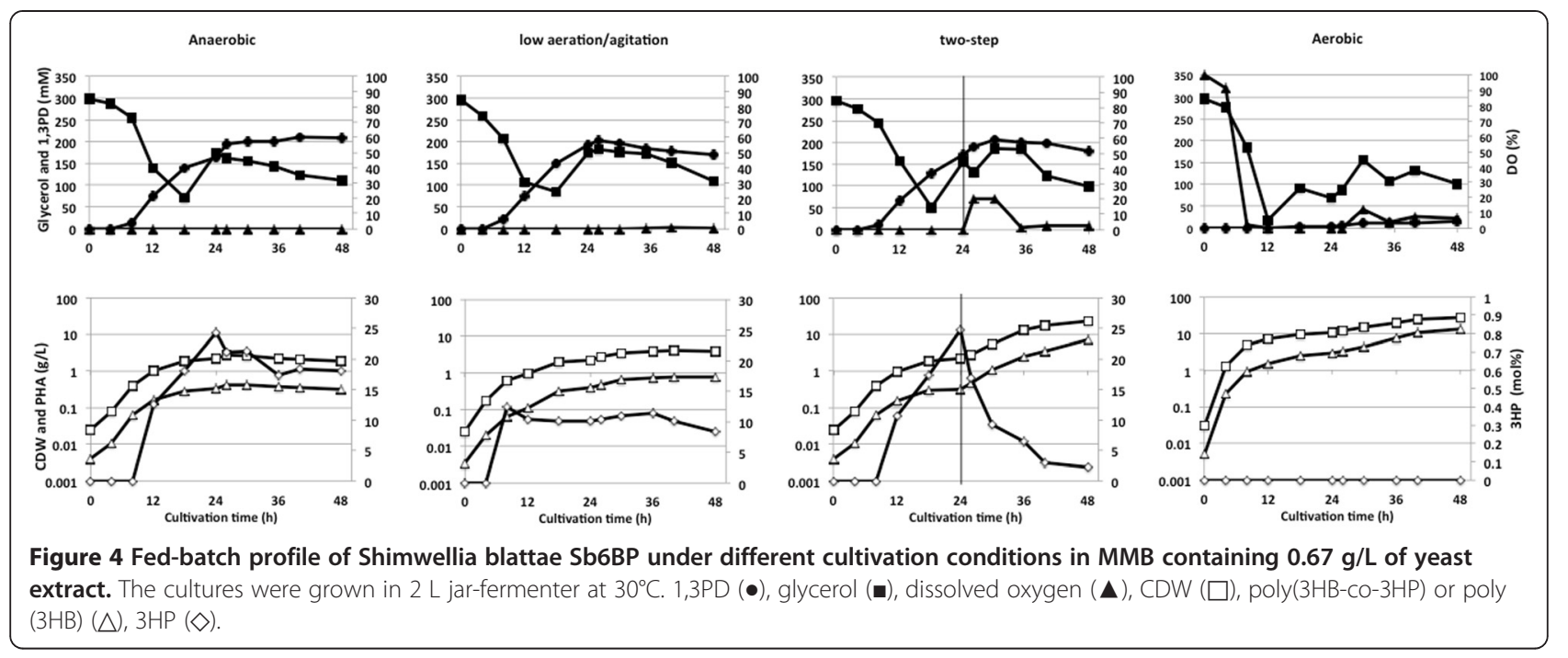

aerobic condition no $3 \mathrm{HP}$ were incorporated as constituent. The productivity for poly (3HB-co-3HP) in BM medium ranged from $4 \mathrm{mg}_{\mathrm{PHA}} / \mathrm{L} / \mathrm{h}$ to $25 \mathrm{mg}_{\mathrm{PHA}} / \mathrm{L} / \mathrm{h}$ and was highest under the two-step condition. No copolymer but poly $(3 \mathrm{HB})$ homopolymer was formed under aerobic conditions, and the productivity for poly $(3 \mathrm{HB})$ was higher in comparison to poly(3HB-co-3HP) in both $\mathrm{BM}$ and MMB medium. The polymer content was also highest in the two-step fermentations $(29.9 \%$ in BM and 30.7\% $\mathrm{wt}_{\mathrm{PHA}} / \mathrm{wt}_{\mathrm{CDW}}$ in MMB, respectively), and lowest (14.7\% in $\mathrm{BM}$ and $17.2 \% \mathrm{wt}_{\mathrm{PHA}} / \mathrm{wt}_{\mathrm{CDW}}$ in $\mathrm{MMB}$, respectively) in the anaerobic fermentation. On the other hand, poly(3HB-co3HP) with the highest $3 \mathrm{HP}$ content was obtained (16.6 mol\% in BM and $18.1 \mathrm{~mol} \%$ in MMB, respectively) in anaerobic fermentations.

The time courses of polymer synthesis for each cultivation condition in BM medium were as follows (Figure 3): (1) Anaerobic: cell growth and addition of ammonium hydroxide almost stopped after $48 \mathrm{~h}$ cultivation time. The highest 3HP composition (20.2 mol\%),
1,3PD concentration $(242 \mathrm{mM})$ and polymer production was recorded after about $40 \mathrm{~h}$ cultivation time. These data indicate that 3HP-CoA and 1,3PD synthesis occurred only during exponential cell growth. Moreover, it was indicated that both, $(R)-3 \mathrm{HB}-\mathrm{CoA}$ and 3HP-CoA are not supplied after the stop of cell growth, because the 3HP content was very stable after $40 \mathrm{~h}$. (2) Low aeration/agitation: the time courses of every parameter except $3 \mathrm{HP}$ monomer fraction were very similar when compared to anaerobic conditions as explained above. The highest molar 3HP monomer fraction was recorded earlier than 12 hour of culture time. The residual cell mass was only marginally influenced by aeration, but the 3HP monomer content of the polyester was decreased to less than $50 \%$ in comparison to anaerobic condition. (3) Two-step: Interestingly, the highest molar 3HP fraction in the copolymer was recorded at the time when the cultivation conditions were just switched. After that, the fraction of 3HP moieties rapidly dropped but the cell dry weight (CDW) increased on the other hand. Formation of 1,3PD was maintained for some hours

Table 2 Results of fed-batch cultivation using Sb6BP and glycerol as sole carbon source

\begin{tabular}{|c|c|c|c|c|c|c|c|c|c|c|}
\hline \multirow[t]{2}{*}{ Strain } & \multirow[t]{2}{*}{ Medium } & \multirow[t]{2}{*}{ Condition } & \multirow{2}{*}{$\begin{array}{l}\text { Cell } \\
\text { density } \\
\left(g_{\mathrm{CDW}} / \mathrm{L}\right)\end{array}$} & \multirow{2}{*}{$\begin{array}{l}\text { PHA } \\
\text { content } \\
\text { (wt\%) }\end{array}$} & \multirow{2}{*}{$\begin{array}{l}\text { PHA } \\
\left(g_{\mathrm{PHA}} / \mathrm{L}\right)\end{array}$} & \multicolumn{2}{|c|}{ Monomer composition (mol\%) } & \multirow{2}{*}{$\begin{array}{l}\text { Cultivation } \\
\text { time (h) }\end{array}$} & \multirow{2}{*}{$\begin{array}{l}\mathrm{PHB}(\mathrm{P}) \\
\text { productivity } \\
\text { (mg }\end{array}$} & \multirow{2}{*}{$\begin{array}{l}\text { Glycerol } \\
\text { yield }\end{array}$} \\
\hline & & & & & & $3 \mathrm{HB}$ & $3 \mathrm{HP}$ & & & \\
\hline \multirow[t]{8}{*}{ Sb6BP } & $\mathrm{BM}$ & Anaerobic & 1.72 & 14.7 & 0.25 & 83.4 & 16.6 & 72 & 3.51 & 0.0041 \\
\hline & & Low aeration/agitation & 2.11 & 24.6 & 0.52 & 92.4 & 7.3 & & 7.21 & 0.0075 \\
\hline & & Two-step & 6.12 & 29.9 & 1.83 & 91.4 & 8.6 & & 25.4 & 0.032 \\
\hline & & Aerobic & 12.6 & 55.2 & 6.96 & 100 & 0 & & 96.6 & 0.097 \\
\hline & $\mathrm{MMB}$ & Anaerobic & 1.84 & 17.2 & 0.32 & 82.9 & 18.1 & 48 & 6.59 & 0.0033 \\
\hline & & Low aeration/agitation & 3.78 & 20.3 & 0.77 & 91.7 & 8.3 & & 16.0 & 0.011 \\
\hline & & Two-step & 23.2 & 30.7 & 7.12 & 97.9 & 2.1 & & 148.4 & 0.093 \\
\hline & & Aerobic & 27.3 & 48.1 & 13.1 & 100 & 0 & & 273.6 & 0.15 \\
\hline
\end{tabular}

Cells were cultivated in MB or MMB medium with glycerol that was intermittently added. MMB contained $0.67 \mathrm{~g} / \mathrm{L}$ yeast extract. Kanamycin was added as $50 \mu \mathrm{g} / \mathrm{ml}$ final concentration at the beginning of the cultivation. All cultivations were conducted in a $2 \mathrm{~L}$ jar-fermenter. 
after the cultivation condition was changed from anaerobic to aerobic and then stopped. (4) Aerobic: only the poly $(3 \mathrm{HB})$ homopolymer was synthesized under aerobic conditions. Furthermore, the cell density $\left(12.6 \mathrm{~g}_{\mathrm{CDW}} / \mathrm{L}\right)$ and the PHA productivity $\left(96.6 \mathrm{mg}_{\mathrm{PHA}} / \mathrm{L} / \mathrm{h}\right)$ were the highest. Only a small amount of 1,3PD (10 to $15 \mathrm{mM}$ ) was synthesized after $24 \mathrm{~h}$ of cultivation, and the $3 \mathrm{HP}$ monomer was not detected by GC analysis at any period.

GPC analysis of the isolated poly(3HB-co-3HP) obtained in BM after two-step cultivation for $72 \mathrm{~h}$ revealed an average molecular weight of $765,293 \mathrm{Da}$ with a polydispersity index $\left(\mathrm{M}_{\mathrm{w}} / \mathrm{M}_{\mathrm{n}}\right)$ of 2.49 .

\section{Optimization of the medium for cultivation}

Although cells of strain Sb6BP could be successfully cultivated, poly $(3 \mathrm{HB}-c o-3 \mathrm{HP})$ productivity was still low due to a low residual cell mass. The cell density was only $12.6 \mathrm{~g}_{\mathrm{CDW}} / \mathrm{L}$ under aerobic condition in $\mathrm{BM}$ medium. From these results it was suspected that some substances required for cell growth were missing or that at least a severe shortage had occurred in BM medium. Therefore, the medium was optimized.

It was confirmed that the growth rate of the cells was influenced by the concentration of yeast extract in the medium (Figure 5). The growth rates $(\mu)$ of the cells in MMB between 0 to $12 \mathrm{~h}$ cultivation time containing 0 , 0.2 or $2.0 \mathrm{~g} / \mathrm{L}$ of yeast extract were $0.32,0.36$ and $0.41 \mathrm{~h}^{-1}$, respectively. It was also confirmed that the trace element solution used in this study is necessary for cell growth (Figure 5A). These results indicate in contrast to our expectations that yeast extract is very important for cell growth of $S$. blattae. Yeast extract contains many vitamins like biotin, 4-aminobenzoic acid, pantothenic acid, pyridoxine, riboflavin and thiamine (data from DIFCO) in addition to amino acids and some of these compounds are likely to be growth limiting.

Although yeast extract was confirmed as a key factor for growth of $S$. blattae, the optimum concentration could not be identified in flask culture experiments since cell growth stopped after $24 \mathrm{~h}$ of cultivation time when the $\mathrm{pH}$ had dropped below 5. Therefore, higher cell density cultivations were conducted in $2 \mathrm{~L}$ fermenter in order to determine the optimum concentration of yeast extract. The cell densities obtained in aerobic cultivations in MMB containing $0.2,0.67$ and $6.7 \mathrm{~g} / \mathrm{L}$ of yeast extract were 14.6, 27.3 and $44.6 \mathrm{~g}_{\mathrm{CDW}} / \mathrm{L}$, respectively (Figure 5B, Table 3).

With regard to the cost, we chose of $0.67 \mathrm{~g} / \mathrm{L}$ to obtain $27.3 \mathrm{~g}_{\mathrm{CDW}} / \mathrm{L}$.

\section{Synthesis of poly(3HB-co-3HP) in MMB medium}

Improved productivities for PHA synthesis were between 1.9 and 5.8 times higher in $\mathrm{MMB}$ than in $\mathrm{BM}$; the highest poly(3HB-co-3HP) productivity was obtained in two-step

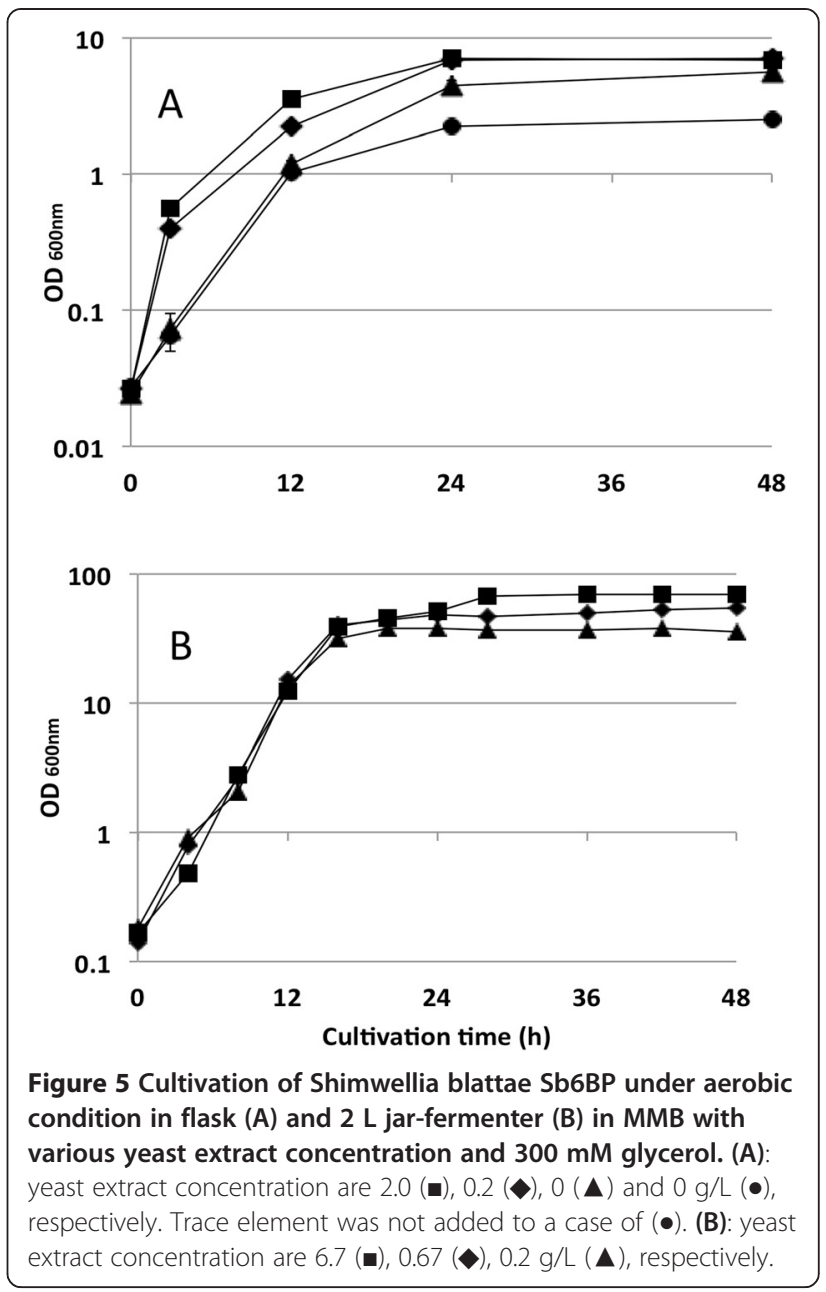

cultivation $\left(25 \mathrm{mg}_{\mathrm{PHA}} / \mathrm{L} / \mathrm{h}\right.$ in $\mathrm{BM}$ medium in comparison to $148 \mathrm{mg}_{\mathrm{PHA}} / \mathrm{L} / \mathrm{h}$ in MMB) (Table 2). The positive effect of MMB medium was highest in two-step cultivation experiments. This is explained by the fact that cell growth was very high after the culture conditions were changed (Figure 4).

Conversely, these effects were less under anaerobic and low aeration/agitation conditions. An explanation is most probably because the rate-limiting factor was oxygen and not one of the compounds included in yeast extract. These observations could not be confirmed in

Table 3 Cultivation of Sb6BP in MMB containing various concentrations of yeast extract

\begin{tabular}{lllll}
\hline $\begin{array}{l}\text { Yeast } \\
\text { extract }(\mathbf{g} / \mathbf{L})\end{array}$ & $\begin{array}{l}\text { Cell density } \\
\left(\mathbf{g}_{\mathbf{C D w}} / \mathbf{L}\right)\end{array}$ & $\begin{array}{l}\text { PHA } \\
\left(\mathbf{g}_{\mathbf{P H A}} / \mathbf{L}\right)\end{array}$ & $\begin{array}{l}\text { PHA content } \\
(\mathbf{w t} \%)\end{array}$ & $\begin{array}{l}\text { Cultivation } \\
\text { time }(\mathbf{h})\end{array}$ \\
\hline 0.2 & 14.6 & 5.58 & 38.3 & 48 \\
0.67 & 27.3 & 14.2 & 48.1 & 48 \\
6.7 & 44.6 & 21.1 & 47.2 & 48 \\
\hline
\end{tabular}

During cultivation, glycerol was intermittently added. Kanamycin was added as $50 \mu \mathrm{g} / \mathrm{ml}$ final concentration at the beginning of the cultivation. All cultivations were conducted in a $2 \mathrm{~L}$ jar-fermenter. 
MMB under aerobic condition as there was no poly (3HB-co-3HP) accumulated. The polymer content and the $3 \mathrm{HP}$ fraction in the copolyester were not so much influenced under anaerobic and low aeration/agitation conditions whereas the 3HP fraction in two-step condition dropped rapidly from 8.6 to $2.1 \mathrm{~mol} \%$ after the cultivation conditions were changed (Figure 4). These results indicate that the decrease of $3 \mathrm{HP}$ fraction might be due to a relative decrease of the monomer composition by additional accumulation of $3 \mathrm{HB}$ and/or poly $(3 \mathrm{HB})$, because, after switching the conditions, cell growth started again and 3HB-CoA provision via acetoacetyl-CoA was started as well. In addition, it was confirmed that the net $3 \mathrm{HP}$ amount increased until $30 \mathrm{~h}$; thereafter no increase occurred in case of two-step cultivation when using the MMB medium. Therefore, there is a possibility that the resulting polymer was likely a blend of poly $(3 \mathrm{HB})$ and poly (3HB-co-3HP).

Poly(3HB-co-3HP) with the highest 3HP fraction (18.1 mol\%) was obtained during anaerobic condition; however, the polymer productivity and cell density were only $6.6 \mathrm{mg}_{\mathrm{PHA}} / \mathrm{L} / \mathrm{h}$ and $1.84 \mathrm{~g}_{\mathrm{CDW}} / \mathrm{L}$, respectively.

\section{Discussion}

In this study we engineered a recombinant strain of $S$. blattae ATCC33430 (Sb6BP), which is able to synthesize poly (3HB) and poly(3HB-co-3HP). However, Sb6BP synthesized the copolymer only under oxygen limiting conditions because the cells produced only small amounts of 1,3-propanediol (1,3PD) as a precursor of 3-hydroxypropionyl-CoA (3HP-CoA) under aerobic condition. In any case, in comparison with the 1,3PD productivity under oxygen limiting conditions, a lower productivity of 1,3PD under aerobic condition causes non-accumulation of poly(3HB-co-3HP).

However, successful production of poly (3HB-co-3HP) in recombinant $S$. blattae was achieved, 3HP composition was rather low. The glass transition temperature of poly $(3 \mathrm{HB}-c o-3 \mathrm{HP})$ decreases rapidly from $-3^{\circ} \mathrm{C}$ to $-15^{\circ} \mathrm{C}$, and the melting temperature $(\mathrm{Tm})$ decreases from $163^{\circ} \mathrm{C}$ to $73^{\circ} \mathrm{C}$ as the $3 \mathrm{HP}$ fraction in the copolymer increased from 25.6 to $36.3 \mathrm{~mol} \%$ (Wang et al., 2013). In particular, the poly(3HB-co-3HP) with a $3 \mathrm{HP}$ content exceeding $30 \mathrm{~mol} \%$ is therefore much more flexible and less crystalline and is expected to approach that of conventional plastics such as polypropylene, polystyrene, and polyethylene. The low 3HP fraction indicates that the strain cannot actively import 1,3PD from culture medium or that 3HP-CoA supply via 3-hydroxypropionaldehyde and 3-hydroxypropionate is insufficient.

This is the first report for the production of poly(3HBco-3HP) without using vitamin $\mathrm{B}_{12}$ and expensive compounds such as 3-hydroxypropionate by recombinant $S$. blattae. We achieved a poly(3HB-co-3HP) productivity of $148 \mathrm{mg}_{\mathrm{PHA}} / \mathrm{L} / \mathrm{h}$ in this study, which is the highest so far reported (Shimamura et al., 1994; Fukui et al., 2009; Wang and Inoue, 2001; Wang et al., 2013). S. blattae is therefore one of the promising bacterial strains for poly (3HB-co-3HP) production from glycerol.

However, the reported processes still require oxygen limitation. Therefore, the polymer productivity is still very low. In addition, the polymer produced by two-step cultivation method was likely a blend of poly $(3 \mathrm{HB})$ and poly (3HB-co-3HP) owing to the conditional change from anaerobic to aerobic condition. The remaining challenges are to achieve efficient utilization of 3HPA or 1,3PD and the expression of the genes regulated by dha regulon in aerobic conditions for aerobic production of poly(3HB-co-3HP). Moreover, an enhancement of the metabolite flow from 3hydroxypropionaldehyde to $3 \mathrm{HP}-\mathrm{CoA}$ will be necessary to increase the 3HP fraction in the copolymer. By using the $p d u P$ gene from Salmonella enterica (Andreeßen et al., 2010) or Salmonella typhimurium (Gao et al., 2014), the provision of 3HP-CoA provision might be improved.

\section{Competing interests}

The authors declare that they have no competing interests.

\section{Authors' contributions}

SS performed the experiments. SS and BA participated in the design of the study. SS and BA drafted the manuscript. AS edited the manuscript. BA and AS conceived the study. All authors read and approved the final manuscript.

\section{Acknowledgement}

We thank Rolf Daniel and his laboratory at the Department of Genomic and Applied Microbiology (Georg-August University Göttingen) for providing S. blattae ATCC 33430 and Kaneka Corporation, Japan, for GPC analysis. We acknowledge support by Deutsche Forschungsgemeinschaft and Open Access Publication Fund of University of Münster.

Received: 29 January 2015 Accepted: 17 February 2015

Published online: 04 March 2015

\section{References}

Anderson AJ, Haywood GW, Dawes EA (1990) Biosynthesis and composition of bacterial poly(hydroxyalkanoates). Int J Biol Macromol 12:102-105

Andres S, Wiezer A, Bendfeldt H, Waschkowitz T, Toeche-Mittler C, Daniel R (2004) Insights into the genome of the enteric bacterium Escherichia blattae: cobalamin $\left(B_{12}\right)$ biosynthesis, $B_{12}$-dependent reactions, and inactivation of the gene region encoding $B_{12}$-dependent glycerol dehydratase by a new Mu-like prophage. J Mol Microbial Biotechnol 8:150-168

Andreeßen B, Johanningmeier B, Burbank J, Steinbüchel A (2014a) Influence of the operon structure on poly(3-hydroxypropionate) synthesis in Shimwellia blattae. Appl Microbiol Biotechnol 98(17):7409-7422

Andreeßen B, Lange AB, Robenek H, Steinbüchel A (2010) Conversion of glycerol to Poly(3-hydroxypropionate) in Recombinant Escherichia coli. Appl Environ Microbiol 76:622-626

Andreeßen B, Steinbüchel A (2010) Biosynthesis and biodegradation of 3hydroxypropionate-containing polyesters). Appl Environ Microbiol 76 (15):4919-4925

Andreeßen B, Taylor N, Steinbüchel A (2014b) Poly(3-hydroxypropionate): A promising alternative to fossil fuel-based materials. Appl, Environ. Microbiol. August, 22 doi:10.1128/AEM. 02361-14

Brandl H, Gross RA, Lenz RW, Fuller RC (1998) Pseudomonas oleovorans as a source of poly( $\beta$-hydroxyalkanoates) for potential applications as biodegradable polyesters. Appl Environ Microbiol 54:1977-1982

Budde CF, Mahan AE, Lu J, Rha C, Sinskey AJ (2010) Role of multiple acetoacetyl coenzyme $A$ reductase in polyhydroxybutyrate biosynthesis in Ralstonia eutropha H16. J Bacteriol 192:5319-5328 
Burgess NR, McDermott SN, Whiting J (1973) Aerobic bacteria occurring in the hindgut of the cockroach, Blatta orientalis. J Hyg 71:1-7

Chen GQ, Wu Q, Zhao K, Yu PH (2000) Functional polyhydroxyalkanoates synthesized by microorganisms. Chinese J Polym Sci 18-5:389-396

Doi Y, Kitamura S, Abe H (1995) Microbial synthesis and characterization of poly (rhydroxybutyrate-co-hydroxyhexanoate). Macromolecules 8:4822-4828

Enayati N, Trai C, Parulekar SJ, Stark BC, Webster DA (1999) Production of r-amylase in fed-batch cultures of vgb + and vgb-recombinant Escherichia coll: some observations. Biotechnol Prog 15:640-645

Fukui T, Suzuki M, Tsuge T, Nakamura S (2009) Microbial synthesis of poly((R)-3hydroxybutyrate-co-3-hydroxypropionate) from unrelated carbon sources by engineered Cupriavidus necator. Biomacromolecules 10:700-706

Gao Y, Liu C, Ding Y, Sun C, Zhang R, Xian M, Zhao G (2014) Development of genetically stable Escherichia coli strains for poly(3-Hydroxypropionate) production. PLoS One 9(5):e97845

Heinrich D, Andreeßen B, Steinbüchel A (2013) From waste to plastic: Synthesis of poly(3-hydroxypropionate). Appl Environ Microbiol 79:3582-3589

Heinrich D, Madkour MH, Al-Ghamdi MA, Shabbaj II, Steinbüchel A (2012) Large scale extraction of poly(3-hydroxybutyrate) from Ralstonia eutropha H16 using sodium hypochlorite. AMB Express 2(1):59

Kovach ME, Elzer PH, Hill DS, Robertson GT, Farris MA, Roop RM 2nd, Peterson KM (1995) Four new derivatives of the broad-host-range cloning vector pBBR1MCS, carrying different antibiotic-resistance cassettes. Gene 166:175-176

Lee SY (1996) Bacterial polyhydroxyalkanoates. Biotechnol Bioeng 49:1-14

Martens JH, Barg H, Warren MJ, Jahn D (2002) Microbial production of VitaminB ${ }_{12}$. Appl Microbial Biotechnol 58:275-285

Priest FG, Barker M (2010) Gram-negative bacteria associated with brewery yeasts: reclassification of Obesumbacterium proteus biogroup 2 as Shimwellia pseudoproteus gen. nov., sp. nov., and transfer of Escherichia blattae to Shimwellia blattae comb. nov. Int J Envol Microbiol 60:828-833

Quispe C, Coronado CJR, Carcalho JA (2013) Glycerol: Production, consumption, price, characterization and new trends in combustion. Renew Sust Energ Rev 27:475-493

Sambrook J, Fritsch EF, Maniatis T (1989) Molecular cloning: A laboratory manual. Cold spring Harbor Laboratory Press. Cold Spring Harbor, NY

Sato S, Tetsuya F, Matsumoto K (2013) Construction of a stable plasmid vector for industrial production of poly(3-hydroxybutyrate-co-3-hydroxyhexanoate) by a recombinant Cupriavidus necator H16 strain. J Biosci Bioeng 116:677-681

Shimamura E, Kasuya K, Kobayashi G, Shiotani T, Shima Y, Doi Y (1993) Physical properties and biodegradability of microbial poly(3-hydroxybutyrate-cohydroxyhexanoate). Macromolecules 27:878-880

Shimamura E, Scandola M, Doi Y (1994) Microbial synthesis and characterization of poly(3-hydroxybutyrate-co-3-hydroxypropionate). Macromolecules 27:4429-4435

Spiekermann P, Rehm BHA, Kalscheuer R, Baumeister D, Steinbüchel A (1999) A sensitive, viable-colony staining method using Nile red for direct screening of bacteria that accumulate polyhydroxyalkanoic acids and other lipid storage compounds. Arch Microbiol 171:73-80

Steinbüchel A (2001) Perspectives for biotechnological production and utilization of biopolymers: metabolic engineering of polyhydroxyalkanoate biosynthesis pathway as a successful example. Macromol Biosci 1:1-24

Steinbüchel A, Füchtenbusch B (1998) Bacterial and other biological systems for polyester production. Trends Biotechnol 16:419-427

Sun J, Heuvel JVD, Soucaille P, Qu Y, Zeng AP (2003) Comparative genomic analysis of dha regulon and related genes for anaerobic glycerol metabolism in bacteria. Biotechnol Prog 19:263-272

Timm A, Byrom D, Steinbüchel A (1990) Formation of blends of various poly(3hydroxyalkanoic acids) by a recombinant strain of Pseudomonas oleovorans. Appl Microbiol Biotechnol 33:296-301

Wang Y, Inoue Y (2001) Effect of dissolved oxygen concentration in the fermentation medium on transformation of the carbon sources during the biosynthesis of poly(3-hydroxybutyrate-co-3-hydroxypropionate) by Alcaligenes latus. Int J Biol Macromol 28:235-243

Wang Q, Yang P, Xian M, Yang Y, Liu C, Xue Y, Zhao G (2013) Biosynthesis of poly(3-hydroxybutyrate-co-3-hydroxypropionate) with fully controllable structure from glycerol. Bioresour Technol 142:741-744

\section{Submit your manuscript to a SpringerOpen ${ }^{\odot}$ journal and benefit from:}

- Convenient online submission

- Rigorous peer review

- Immediate publication on acceptance

- Open access: articles freely available online

- High visibility within the field

- Retaining the copyright to your article

Submit your next manuscript at $\gg$ springeropen.com 